\title{
The dermal toxicity of phenol: an investigation of the most effective first-aid measures
}

\author{
D. M. CONNING and M. J. HAYES \\ Imperial Chemical Industries Limited, Industrial Hygiene Research Laboratories, \\ Alderley Park, near Macclesfield, Cheshire
}

\begin{abstract}
Conning, D. M., and Hayes, M. J. (1970). Brit.J.industr.Med.,27,155-159. The dermal toxicity of phenol: an investigation of the most effective first-aid measures. The percutaneous toxicity of phenol in the Alderley Park (Wistar derived specific pathogen free) rat was determined and was shown to be increased by the diluents water, methylated spirit or olive oil. The toxicity was related to the degree of dermal damage in one minute, and this was greatest when the phenol was diluted $1: 1$ or $2: 1$. First-aid procedures were investigated, and the following is recommended:

1. Remove all clothing as quickly as possible. First-aiders must take care to avoid contaminating themselves.

2. Swab all contaminated skin with cotton wool soaked in glycerol, polyethylene glycol or a polyethylene glycol/methylated spirit mixture for at least 10 minutes. Airtight bins containing such swabs should be located wherever large volumes of phenol are in use.

3. Remove the patient to a place equipped with resuscitation equipment and observe for 24 hours.
\end{abstract}

Phenol is a powerful and corrosive contact poison, and absorption through the skin is very rapid (Sax, 1968). The immediate first-aid treatment for people exposed by skin contact may, therefore, be a lifesaving procedure. Phenol is soluble in alcohol, oil, and, to a lesser degree, water, and all of these materials have, at different times, been recommended as suitable agents for first-aid treatment, the procedure usually suggested being to flood the affected area until a phenolic odour is no longer detectable (Deichmann, Witherup, and Dierker, 1952). There is some confusion which of the materials is the most efficient, and it has been suggested that water itself may increase the toxicity of phenol (Freeman, Draize, and Alvarez, 1951). The work reported here was undertaken to determine how the materials usually recommended affected the toxicity of phenol applied to the skin, and which, if any, could be recommended for use in first-aid therapy.

\section{Materials and methods}

The animals used were adult female rats of the Alderley Park specific pathogen free strain, weighing between 175 and $200 \mathrm{~g}$. They were housed in groups of five in wire-mesh cages and given standard rat cubes (Oaks of Congleton, Cheshire) and water ad libitum.

Phenol was laboratory reagent grade (British Drug Houses) with a melting point of $39 \cdot 5-41^{\circ} \mathrm{C}$. It was warmed in a water-bath until melted and maintained in this state at approximately $40^{\circ} \mathrm{C}$. Applications were made with a 1-ml syringe and needle which were kept partially immersed in the phenol to obviate crystallization within the syringe. After treatment all animals were caged individually.

Percutaneous toxicity of phenol

This was examined by an occlusive technique in which a single application was made to the shorn backs of groups of five rats and the treated areas were covered with polythene held in place by waterproof adhesive dressing 
(Sleek). The different groups received $1.0,0.5,0.25$ or $0.1 \mathrm{ml} / \mathrm{kg}$ body weight, and after 24 hours the dressings were removed and the skin was cleaned with a mild detergent. In a second experiment a non-occlusive technique was employed in which the treated area was left uncovered, and the animals were prevented from cleaning the site of application by means of a rigid plastic collar applied round the neck. The dose levels in this case were $1.0,0.75,0.5$, and $0.1 \mathrm{ml} / \mathrm{kg}$ body weight and the skin was again cleaned after 24 hours.

Percutaneous toxicity of solutions of phenol in water, $2.5 \%$ cetrimide, methylated spirit or olive oil

These were assessed in groups of five rats using the non-occlusive technique described above. In each case three concentrations of phenol were examined, namely, $66 \%, 50 \%$ and $33 \%$, but the volumes were adjusted so that the animals received $0.5 \mathrm{ml} / \mathrm{kg}$ body weight of phenol. In each case a control group of five female rats received $0.5 \mathrm{ml}$ of undiluted phenol/kg body weight.

To assess the first-aid procedures, groups of three female rats were treated with $1 \mathrm{ml}$ of undiluted phenol/kg body weight, and the site of application was washed after one minute, three minutes or five minutes with water, $2.5 \%$ cetrimide, methylated spirit or olive oil. Treatment was effected by pouring large amounts of the material on the skin.

Groups of three animals treated with $1 \mathrm{ml}$ phenol/kg body weight were treated after one minute by swabbing with cotton wool soaked in water, $2.5 \%$ cetrimide, methylated spirit or olive oil.

Groups of five animals given skin applications of $1 \mathrm{ml}$ phenol $/ \mathrm{kg}$ body weight were treated after one minute by swabbing with cotton wool soaked in glycerol, polyethylene glycol (grade 300) or water; or water followed five minutes later by olive oil. As controls, groups of three animals treated similarly with phenol were subjected after one minute to swabbing with cotton wool alone or were left untreated. In this experiment the swabbing was continued for a fixed time of 15 seconds, whereas in previous experiments it was untimed but continued for less than 10 seconds.

All animals which survived the above procedures were observed for seven days and were then killed and subjected to post-mortem examination. The kidneys and skin were examined histologically.

\section{Results}

\section{Percutaneous toxicity of phenol}

By both occlusive and non-occlusive techniques the percutaneous $\mathbf{L D}_{50}$ was $0.625 \mathrm{ml} / \mathrm{kg}$ body weight. Clinically, all the animals behaved similarly. Between five and 10 minutes after dosing they developed severe muscle tremors causing marked twitching which developed into generalized convulsions with loss of consciousness and prostration. At varying times between 45 minutes and 90 minutes, depending upon the dose administered, the animals developed severe haemoglobinuria. Rats receiving $1 \mathrm{ml}$, and two of those receiving $0.5 \mathrm{ml}$, died within four hours of treatment by the occlusive technique; by the other method, all receiving $1 \mathrm{ml}$ and $0.75 \mathrm{ml}$ died within 24 hours, but there were no other deaths. All animals showed severe skin lesions with immediate onset of oedema followed within four hours by necrosis associated at 24 hours with discoloration and surrounding erythema. At necropsy those animals dying in the acute stage from phenol poisoning showed renal congestion, and the urinary bladders were distended with blood-stained fluid. On histological examination the kidneys showed haematin casts in the distal convoluted tubules and in the tubules of the medulla and papillae. The skin showed extensive epidermal necrosis characterized by a hyaline appearance of the cells, loss of intercellular processes, and deposition of eosinophilic debris in the intercellular spaces. There was extensive superficial necrosis of the dermis, which was stained a purple colour by haematoxylin and eosin, suggesting a coagulative type of necrosis.

Percutaneous toxicity of solutions of phenol in water, $\mathbf{2 . 5} \%$ cetrimide, methylated spirit or olive oil

Rats were given $0.5 \mathrm{ml} / \mathrm{kg}$ of phenol in all experiments.

Phenol/water (Fig. 1) All the animals showed severe muscle tremors within 10 minutes of dosing,

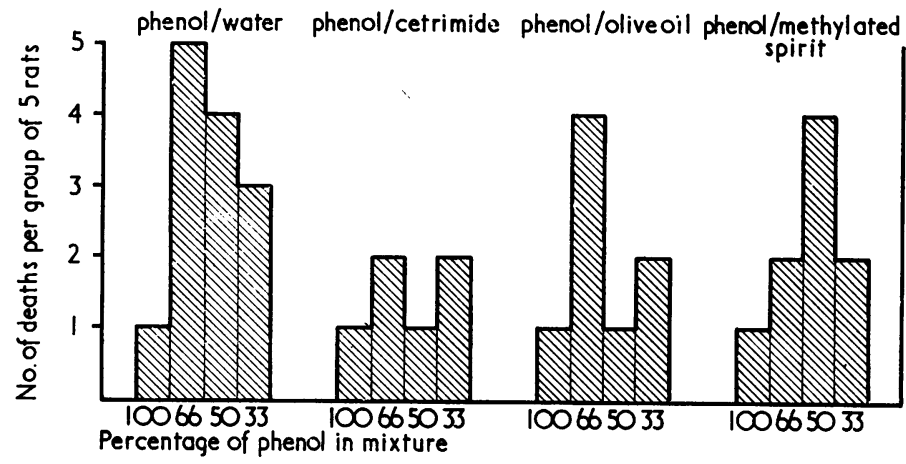

FIG. 1. Mortalities observed at six hours in animals treated with various concentrations of phenol in different diluents. In each case the animals received $0.5 \mathrm{ml} \mathrm{phenol} / \mathrm{kg}$ body weight. 
and this persisted in the surviving animals for four to six hours. All the animals receiving $66 \%$ phenol died within five hours, as did four receiving $50 \%$ and three receiving $33 \%$. Only one animal receiving undiluted phenol died. At 24 hours the surviving animals appeared normal, apart from the skin lesions. Post-mortem examination showed changes similar to those already described, but histologically the extent of the dermal necrosis was less in animals treated with diluted phenol than in those treated with the undiluted material.

Phenol/cetrimide The clinical response was much the same as that described above, but the mortalities (Fig. 1) showed no significant difference between the different concentrations of phenol applied. The histological findings were similar to those described for undiluted phenol.

Phenol/olive oil The early clinical effects were unchanged, and dilution of phenol to $66 \%$ again produced the most severe effects, the other concentrations being no different from the undiluted phenol (Fig. 1). Post-mortem findings were similar except that one animal receiving $66 \%$ phenol showed normal kidneys.

Phenol/methylated spirit Again the clinical findings were as described, and the mortalities (Fig. 1) showed that in this case the $50 \%$ dilution was the most toxic. Post-mortem findings were as before.

Effects of treatment of undiluted phenol (Fig. 2)

The only material to have any effect at all on the toxicity of the phenol was olive oil, and this was to prolong the interval between treatment and death in one of the two animals which died, when applied one minute after the phenol. Some delay was also seen with olive oil when treatment was delayed for five minutes. In each case the eventual mortality remained high. When a swabbing procedure was used, treatment was started one minute after poisoning and in these conditions the mortalities were generally reduced, but again olive oil proved superior to the other agents. In all of these animals the post-mortem findings and subsequent histological findings were as previously described.

Effects of treatment by glycerol, polyethylene glycol grade 300, water followed by olive oil, and water alone In these experiments treatment was started one minute after application of phenol and swabbing was continued for 15 seconds. The results (Table 1) indicate that glycerol, polyethylene glycol, and water followed by olive oil are as good as those obtained with olive oil alone and superior to the other treatments. In this experiment it was shown that dry swabbing alone was ineffective. Those animals treated with water alone in this experiment did better than in previous experiments, presumably because the duration of swabbing was increased. A final experiment was undertaken to compare the

TABLE 1

Effects of Treatment after Applying $1 \mathrm{~mL}$ Phenol/Kg Body Weight to the SKin of Rats

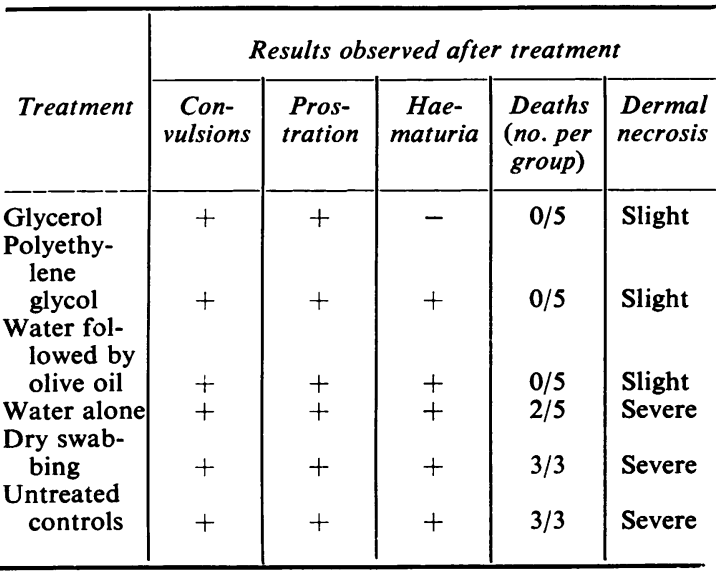

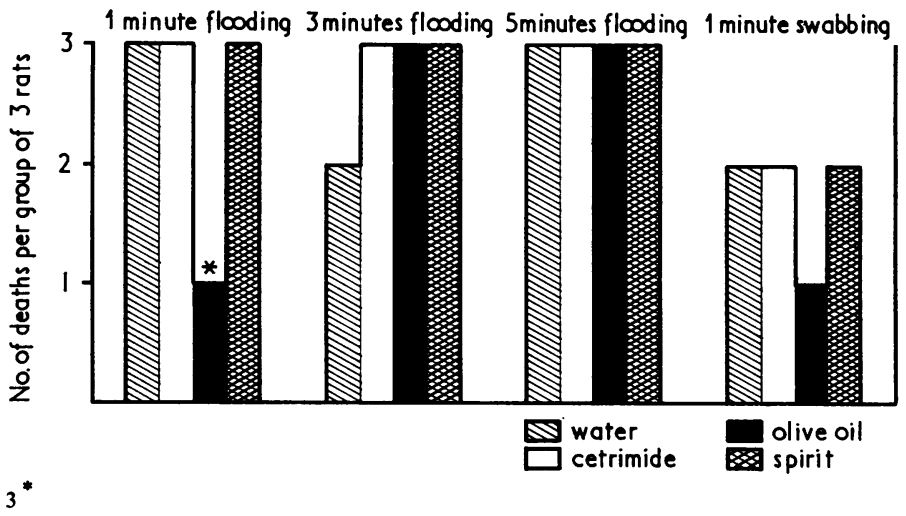

FIG. 2. Mortalities observed at 24 hours in animals exposed to $1 \mathrm{ml}$ phenol/kg body weight, and treated at 1,3 and 5 minutes by flooding or swabbing with the specified material. *One further animal died at 96 hours. 
efficacy of treatment with polyethylene glycol/ methylated spirit mixtures $(70: 30)$, which are less viscous and, therefore, more easily handled. These were compared with polyethylene glycol alone, glycerol alone, and a glycerol/water mixture (50:50) of comparable viscosity to the polyethylene glycol/ methylated spirit mixture. The results (Table 2) show that the polyethylene glycol/methylated spirit

TABLE 2

A Comparison of the Efficacy of Treatment WITH MIXTURES

\begin{tabular}{|c|c|c|c|c|}
\hline \multirow[b]{2}{*}{ Treatment } & \multicolumn{4}{|c|}{ Results observed after treatment } \\
\hline & $\begin{array}{c}\text { Con- } \\
\text { vulsions }\end{array}$ & $\begin{array}{c}\text { Pros- } \\
\text { tration }\end{array}$ & $\begin{array}{c}\text { Hae- } \\
\text { maturia }\end{array}$ & $\begin{array}{c}\text { Deaths } \\
\text { (no. per } \\
\text { group of } \\
5 \text { rats) }\end{array}$ \\
\hline $\begin{array}{l}\text { Polyethylene } \\
\text { glycol-methy- } \\
\text { lated spirits } \\
\text { Glycerol/water } \\
\text { Polyethylene } \\
\text { glycol } \\
\text { Glycerol } \\
\text { Untreated }\end{array}$ & $\begin{array}{l}+ \\
- \\
+ \\
+ \\
+\end{array}$ & $\begin{array}{l}+ \\
- \\
- \\
+ \\
+\end{array}$ & $\begin{array}{l}+ \\
+ \\
+ \\
+ \\
+\end{array}$ & $\begin{array}{l}0 \\
1 \\
0 \\
0 \\
5\end{array}$ \\
\hline
\end{tabular}

mixture is no less efficient than the polyethylene glycol or glycerol alone. In terms of mortalities the glycerol/water mixture was slightly less satisfactory.

\section{Discussion}

Phenol rapidly penetrated the skin of rats to produce generalized stimulation of motor nerve endings or spinal motor centres with possible central depression. It also resulted in haemoglobinuria possibly due to widespread intravascular haemolysis. The severity of its effect was markedly influenced by the diluents and by its concentration in them (Fig. 3). The most toxic mixtures were not necessarily those containing the highest proportion of phenol. For example, $2: 1$ mixtures of phenol and water or olive oil were the most toxic of all, whereas $1: 1$ mixtures with olive oil or cetrimide were the least toxic, and did not differ from undiluted phenol. In general the phenol/aqueous cetrimide mixtures were least hazardous, whereas the mixtures with methylated spirit or olive oil varied in toxicity according to the concentration. At each concentration a phenol/water mixture appears to be more toxic than any other mixture studied. As phenol/aqueous cetrimide was least toxic, it was disappointing to find that aqueous cetrimide had little therapeutic effect and that methylated spirit and olive oil were more satis- factory. It was clear that the rapid dilution of contaminating phenol by means of olive oil was likely to prove the most effective.

An explanation for the variation in toxicity possibly lies in the ability of phenol to provoke a coagulative necrosis which may well slow further penetration, thus allowing time for the residual material to be removed from the epidermis and upper dermis. It seems at least a possibility, therefore, that phenol rapidly penetrates the epidermis but causes a marked necrosis in the upper dermis, thus forming a barrier to its further absorption. Dilution of the phenol, although reducing the amount of phenol available, may also reduce the immediate necrotizing action and thus, paradoxically, aid absorption. The balance must be a fairly fine one, for further dilution reduces the toxicity of the phenol, and it would appear that an approximately 2:1 mixture of phenol and its diluent is the concentration most favouring absorption. In the present study the toxicity of the phenol was approximately inversely proportional to the degree of dermal damage caused within one minute, and was not related to the eventual extent of damage. This finding tends to support the hypothesis outlined above. Deichmann et al. (1952) also found with rabbits that the dermal damage retarded the absorption of phenol.

It follows that the best emergency treatment will be to force an effective diluent into the epidermis before the phenol which is retained there can be absorbed through the necrotic barrier it has created. Although the epidermis itself is necrosed and is, therefore, likely to be highly permeable, the deposition of coagulated protein in the intercellular spaces appears to interfere with the ability of other

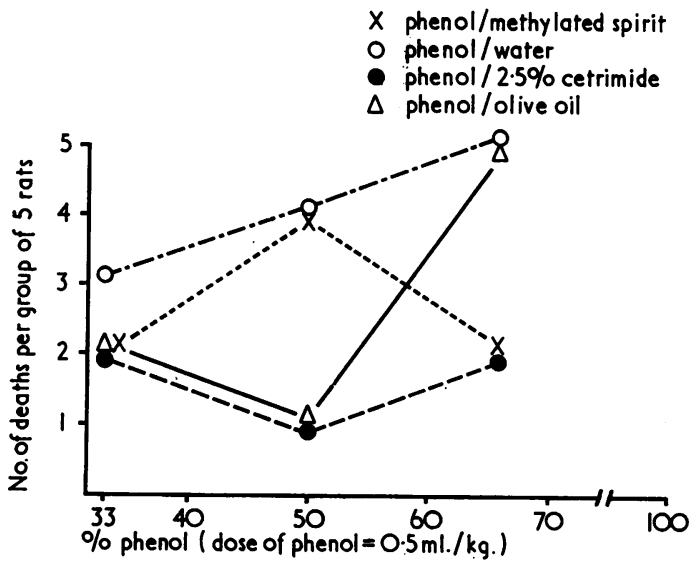

FIG. 3. The percutaneous toxicity of phenolic mixtures. 
liquids to penetrate, with the result that merely pouring fluid on to the affected skin, as recommended by Deichmann (1949), is ineffective (Fig. 2). The swabbing procedure, on the other hand, seems to aid these materials to penetrate, presumably by removing the superficial layers of necrotic keratin. Certainly the mechanical action of swabbing itself is ineffective, but when done with swabs soaked in olive oil, glycerol or polyethylene glycol a substantial therapeutic effect is achieved. In man, where the keratinized and cellular layers of the epidermis are thicker, it is likely that considerable amounts of phenol will be trapped in this region, and that more time will be available for first aid. It is equally likely that a swabbing procedure will be required in order to allow the first-aid material to get to the site of retained phenol, and that simple drenching procedures can do no more than remove excess phenol from the skin surface.

Although olive oil proved effective in the earlier experiments it is open to several criticisms as a first-aid measure. It is difficult to use, because the swabs soaked in it are slimy; it may not be easily available unless containers are provided at suitable sites, in which case they require careful maintenance because of the likelihood of infection. For these reasons, other materials were sought. Glycerol and polyethylene glycol were examined as being materials easily obtainable and requiring little maintenance, and both proved effective. Attempts were made to use water, the most commonly available material, in various combinations, but the results were erratic and usually the treated animals showed greater morbidity.

These considerations are of great importance in man, whose skin is more keratinized and possibly offers slightly more resistance to penetration by phenol. First-aid measures may be truly life-saving. The following procedures are recommended for trial:

1. Remove all contaminated clothing as quickly as possible.

2. Swab all contaminated skin with cotton wool swabs soaked in glycerol, polyethylene glycol or a polyethylene glycol/methylated spirit mixture. Air-tight bins containing such swabs should be located wherever large volumes of phenol are in use. Swabbing should continue for $\mathbf{1 0}$ minutes.

3. Remove the patient to a place with resuscitation equipment and observe for 24 hours.

Personnel giving first-aid should take care to avoid contamination of their own skin.

It is not, of course, possible to predict the efficiency of treatment of percutaneous poisoning in man from experiments in the rat; but in the case of phenol the rat is probably the more sensitive, and the results are, therefore, encouraging. It is to be hoped that in due course records of the results of this treatment in man will prove equally satisfactory.

We are grateful to Dr. A. A. B. Swan and Dr. E. C. Holdsworth for their criticism and advice.

\section{References}

Deichmann, W. B. (1949). Local and systemic effects following skin contact with phenol-a review of the literature. J. industr. Hyg., 31, 146-154.

, Witherup, S., and Dierker, M. (1952). Phenol studies XII. The percutaneous and alimentary absorption of phenol by rabbits with recommendations for the removal of phenol from the alimentary tract or skin of persons suffering exposure. $J$. Pharmacol. exp. Ther., 105, 265-272.

Freeman, M. V., Draize, J. H., and Alvarez, E. (1951). Cutaneous absorption of phenol. J. Lab. clin. Med., 38, 262-266.

Sax, N. I. (1968). Dangerous Properties of Industrial Materials, 3rd ed., p. 1007. Reinhold, New York.

Received for publication July 31, 1969. 